\title{
A Case of Henoch - Schonlein Purpura Nephritis in a Limited Resource Setting
}

\section{Agaprita Sirait}

RSUD Bajawa, Ngada District, East Nusa Tenggara, Indonesia

\section{Correspondence:}

Agaprita Sirait

RSUD Bajawa, Ngada District,

East Nusa Tenggara, Indonesia

E-mail: agaprita@yahoo.com

DOI: $10.3126 /$ jnps.v41ii2.33484

Submitted on: 2020-08-19

Accepted on: 2021-02-14

Acknowledgements: None

Funding: Nil

Conflict of Interest: None declared

Permission from IRB: Yes
To cite this article: Sirait A. A Case of Henoch-Schonlein Purpura Nephritis in A Limited Resource Setting. J Nepal Paediatr Soc. 2021;41(2):266-9.

\section{ABSTRACT}

Henoch-Schonlein Purpura (HSP) is the commonest vasculitis in children, and the outcome depends on renal involvement or occurrence of HSP nephritis (HSPN). Hence, a meticulous diagnosis, treatment and regular follow-up plan is needed for a better prognosis. A case of 12 - year - old girl showing HSPN symptoms only eight weeks after the first onset of HSP is reported. Symptoms of HSPN might appear later, hence emphasising the importance of close monitoring in a patient of HSP. There is a lack of clear consensus about the management of HSPN until now, and it becomes a challenge especially in a limited resource setting like ours. In our case, the patient was treated with corticosteroids.

Key words: nephritis; purpura; Schoenlein-Henoch; vasculitis 


\section{INTRODUCTION}

Henoch-Schonlein Purpura (HSP) is the commonest vasculitis in children. It has an annual incidence of up to 10 - 20 cases per 100,000 children. ${ }^{1}$ HSP is generally considered favourable in terms of both short - term and long - term outcomes, with complete resolution of symptoms. Nonetheless, the long - term morbidity depends on renal involvement or HSP nephritis (HSPN), which occurs in $30-50 \%$ of children with HSP. ${ }^{2}$

The symptoms of HSPN, which are haematuria and proteinuria, usually manifest in four to six weeks after the first presentation of HSP. ${ }^{2}$ At present, there is a lack of clear consensus on the management of HSPN in children. Corticosteroid therapy remains controversial, but initiation of early treatment has the benefit of shortened abdominal pain duration and might prevent development of chronic kidney disease. ${ }^{1}$ In this case, the patient showed renal involvement only after eight weeks of the first complaint, accompanied by severe abdominal pain. Considering the management of HSP and HSPN in a remote area with limited resource setting, patient was given corticosteroid therapy.

\section{CASE REPORT}

A 12 year old girl came to a paediatric clinic in remote area, with complaints of red spots and pain in both the legs. One month before, the patient had already been admitted to the hospital with the complaint of abdominal pain. All the investigations including abdominal USG, blood tests, and urinalysis were within normal range. There was no history of fever, sore throat, cough, and runny nose. Patient is the fourth of five children, developmentally normal child with no significant perinatal or past history. There was no family history of similar complaints in the past.

On physical examination, patient weighed $34 \mathrm{~kg}$ and height was $125 \mathrm{~cm}$. Vital parameters were within normal limits. On examination of the lower limbs, there were multiple palpable, erythematous, non pruritic purpura with a diameter of $1-5 \mathrm{~mm}$ extending from the lower limbs upto the buttock region. After four days, purpura became more progressive and spread to both arms and face. There was also complaint of pain in both legs which was aggravated by movement. Other examinations were in normal range. Laboratory examination showed normal findings with: $\mathrm{Hb} 11.5$ $\mathrm{g} / \mathrm{dL}$, het $36.1 \%$, leukocyte $7600 / \mathrm{mm}^{3}$, thrombocyte $301000 / \mathrm{mm}^{3}$, urea $10 \mathrm{mg} / \mathrm{dL}$ and creatinine 0.15 $\mathrm{mg} / \mathrm{dL}$. Urinalysis was in normal range.

Patient was diagnosed with HSP according to the clinical presentation and laboratory examination. Patient was then managed by intravenous fluid resuscitation, intravenous ranitidine $35 \mathrm{mg}$ two times a day, and oral ibuprofen $400 \mathrm{mg}$ three times a day. After 12 days, the pain and purpura were relieved and patient was allowed to go home. Three days after dismissal, the patient came for follow-up, but by this time the purpura came back to both the legs and even at the soles, with pain even though not as great as before. Patient was admitted once again. After eight days during the hospital stay, the patient complained of abdominal pain with bloodstain in the urine. The urinalysis showed erythrocytes $+3(97 \%$ eumorphic and $3 \%$ dysmorphic), with negative protein.

Thus, the patient was then diagnosed with HSPN. She was treated with intravenous fluid resuscitation, intravenous methylprednisolone 12 $\mathrm{mg}$ three times a day, intravenous ranitidine $35 \mathrm{mg}$ two times a day, and oral ibuprofen $400 \mathrm{mg}$ three times a day. After 12 days, the purpura and pain subsided and the patient was dismissed with oral methylprednisolone $8 \mathrm{mg}$ three times a day and oral ibuprofen $400 \mathrm{mg}$ three times a day. Three days after the dismissal, the patient came again for control and urinalysis was performed. The urinalysis showed there was presence of hematuria with erythrocyte +2 and was closely monitored.

\section{DISCUSSION}

According to American College of Rheumatology (ACR), criteria of HSP must fulfill minimum two of: (1) age 20 years or below at disease onset; (2) palpable purpura; (3) acute abdominal pain; (4) biopsy showing granulocytes in the walls of small arterioles and / or venules. ${ }^{3}$ In this case, abdominal pain had preceded manifestation of purpura by five weeks, hence masking the diagnosis of HSP beforehand.

HSP with renal involvement (HSPN) is one of the most common secondary glomerular diseases. The risk factors associated with HSPN are still unclear, but genetic factors, epidemiological factors, clinical features, and some abnormal laboratory findings may have a predictive value. In cases of HSPN, 
immune complexes deposit at the mesangium, subepithelial and renal subendothelial spaces. These immune complexes activate complement system pathway and also stimulate renal mesenchymal cells to produce chemokines like TNF-alpha and TGF-beta causing inflammation and vasculitis. ${ }^{4,5}$

Generally, patients with HSPN would have hematuria and / or proteinuria within four to six weeks after the onset of the symptoms of HSP. ${ }^{6}$ However, in this case the patient showed manifestations of renal involvement only eight weeks after the first symptom. Most of the patients with HSPN have mild symptoms with high rate of resolution. However, close monitoring is needed, since $1 \%-7 \%$ of the patients may progress to end stage renal disease approximately 20 years after diagnosis. $^{7}$

Until now, the management of HSPN is still evolving. The 2019 Single Hub and Access point for paediatric Rheumatology in Europe (SHARE) recommends early corticosteroid intervention even in cases with mild proteinuria. The delay of potentially effective agents might predispose the patients to ESRD. In severe cases, intravenous cyclophosphamide with pulsed methylprednisolone and / or oral prednisolone may be given to induce remission, and corticosteroids in lower dose combined with azathioprine or mycophenolate mofetil as maintenance therapy. Even in mild nephritis, patients must be routinely monitored to detect any deterioration in kidney function which needs further examination such as renal biopsy. ${ }^{8}$ In this case, after routine examination from the onset of first symptom until the last control appointment, which was ten weeks duration in total, the hematuria had been still present. Therefore, further diagnostic assessment such as renal biopsy is needed to determine the appropriate management, and to prevent deterioration of the kidney status. Since ours is a resource limited primary set up, patient has been planned to be referred to a paediatric nephrologist for further management.

\section{CONCLUSIONS}

This case report underlines the need for close monitoring of HSP patient, since the symptoms of HSPN might appear late, which contributes to the morbidity and outcome of the patient. In a limited resource setting, management of HSPN with corticosteroids is beneficial in relieving the symptom of pain, but further effect in reducing the progression of renal disease, as seen in the form of relief of haematuria and proteinuria, still needs more observation.

\section{REFERENCES}

1. Trnka P. Henoch-Schönlein purpura in children. J Pediatr Child Heal. 2013;49(12):995-1003. DOI: https://doi.org/ 10.1111/jpc. 12403

2. Chen J, Mao J. Henoch-Schönlein purpura nephritis in children: incidence, pathogenesis and management. World J Pediatr. 2015;11(1):29-34. DOI: https://doi.org/10.1007/s12519-014-0534-5

3. Ozen S, Pistorio A, Iusan SM, Bakkaloglu A, Herlin T, Buoncompagni A, et al. EULAR / PRINTO / PRES criteria for Henoch-Schönlein purpura, childhood polyarteritis nodosa, childhood Wegener granulomatosis and childhood Takayasu arteritis: Ankara 2008. Part II: Final classification criteria. Ann Rheum Dis. 2010;69(5):798-806. DOI:https://doi.org/10.1136/ard.2009.116657

4. Sohagia AB, Gunturu SG, Tong TR, Hertan HI. Case Report Henoch-Schonlein Purpura-A Case Report and Review of the Literature. Gastorenterology Research and Practice. 2010;2010:1-7. DOI: https://doi.org/ $10.1155 / 2010 / 597648$

5. Guo C-P, Lu C. Risk Factors for Renal Involvement in Patients with Immunoglobulin A Vasculitis/HenochSchönlein Purpura. Int J Dermatology Venereol. 2019;2(2):84-8. DOI: https://doi.org/ 10.1097/01.JD9.0000559510.85685.c9

6. Pohl M. Henoch-Schönlein purpura nephritis. Pediatr Nephrol. 2015;30(2):245-52. DOI: https://doi.org/10.1007/ s00467-014-2815-6

7. Nickavar A. Treatment of Henoch Schonlein nephritis; new trends. Soc Diabet Nephrop Prev. 2016;5(4):116-7. DOI: https://dx.doi.org/10.15171/jnp.2016.21 
8. Namgoong M. Management of IgA vasculitis nephritis (Henoch-Schonlein purpura nephritis) in Children. Child Kidney Dis. 2020;24(1):1-13. DOI: https://doi.org/10.3339/jkspn.2020.24.1.1 